\title{
Mathematics Resilience and Achievement Goals: Exploring the Role of Non-Cognitive Factors to Mathematics Performance of University Students amidst of Pandemic
}

\author{
Christopher R. Vergara \\ College of Education, Nueva Ecija University of Science and Technology, Cabanatuan City, Philippines \\ Email: sirvergara23@gmail.com
}

How to cite this paper: Vergara, C.R. (2021) Mathematics Resilience and Achievement Goals: Exploring the Role of Non-Cognitive Factors to Mathematics Performance of University Students amidst of Pandemic. Open Access Library Journal, 8: e8166. https://doi.org/10.4236/oalib.1108166

Received: November 8, 2021

Accepted: December 25, 2021

Published: December 28, 2021

Copyright $\odot 2021$ by author(s) and Open Access Library Inc.

This work is licensed under the Creative Commons Attribution International License (CC BY 4.0).

http://creativecommons.org/licenses/by/4.0/

\begin{abstract}
The primary aim of this paper is to determine the association of non-cognitive factors and skills such as mathematics resilience and achievement goals to mathematics performance of the university students. The participants were 69 teacher education students enrolled in a calculus class. Descriptive-correlational research design was used in this study with survey questionnaire as primary tool for data gathering. Moreover, the researcher utilized frequency count, percentage, mean, standard deviation, and Pearson's $r$ to statistically analyze the data. The results revealed that respondents had good mathematics performance. In addition, majority of the students had high level of value and mastery-approach goals. Moreover, analysis reveals that value had significant association to mathematics performance. Mastery-approach and mathematics performance also indicate significant association.
\end{abstract}

\section{Subject Areas}

Education, Social Science, Psychology

\section{Keywords}

Mathematics Resilience, Achievement Goals, Mathematics Performance

\section{Introduction}

The Coronavirus disease (COVID-19) made devastating effect on how we live our lives today. It forces us to adjust and cope with the changes. In education sector, it drastically transforms the teaching and learning process. Educational 
institutions were forced to shift modalities from traditional face-to-face learning to online learning. The utilization of technology enables education system to continue amidst of the pandemic; however, the sudden shift also brought adverse effect in the teaching and learning process [1].

Mathematics is one of the subject matters that is greatly affected by the change of modalities. Numerous challenges and difficulties were experienced by the teachers and students in the implementation of online learning. Despite of the adversities, mathematics education must continue to strive, since it serves as essential tool for social development and global competitiveness. Indeed, Filipino students need to develop mathematics proficiency and literacy to build a solid intellectual resource foundation, as economic progress relies heavily on the development of science, technology, engineering, and mathematics [2]. However, the recent trends in International Mathematics and Science Study (TIMSS) in 2019, the Philippines ranked lower most in mathematics and science out of 58 countries that participated in this extensive international assessment [3].

Mathematics anxiety has been a significant concern in the teaching and learning of the subject matter. It refers to the feeling of dread, tension, and apprehension as students participate in mathematics activities. The unexpected shift of modalities may further increase the risk to students. Numerous research studies provide pieces of evidence that a high level of mathematics anxiety directly impacts mathematics performance and achievement [4] [5]. Adequate attention was already given to this matter, and possible negative effects were relatively well established, particularly in mathematics performance. Hence, a need to develop positive adaptive attitudes toward mathematics will enable students to continue learning despite having to deal with obstacles and difficulties [6].

Psychologists and educational scholars identified non-cognitive factors, skills, and traits, play a crucial role in educational success and achievement. Non-cognitive factors and skills are as important as, if not more important than, cognitive aspects in the educational process and employment potential [7]. The study of [8] found that not all cognitive variables significantly affect the academic performance of high-risk students. It is concluded academic success cannot rely exclusive on cognitive factors and non-cognitive factors were noteworthy to better understand the underlying factors of student's success and failure. Furthermore, [9] explored the importance of non-cognitive variables. The regression analysis showed that grit was a key variable in explaining educational outcome and has a positive impact on the achievement. Mathematics resilience and achievement goals were considered part of this affective construct.

Resilience is the capacity of individuals to confront and respond positively to unpleasant conditions that are inevitable and to take advantage of those unpleasant conditions into an opportunity for personal self-development [10]. In relation to learning mathematics, mathematics resilience is defined as a positive adaptive stance to mathematics. It is an ability that allows students to continue 
learning despite of adversities and learning barriers [11]. In addition, mathematical resilience shares many characteristics with such constructs as self-efficacy, optimism, motivation, and confidence. It is a "can do" attitude toward any new mathematics encountered, a willingness to put an effort to develop fluency, and the ability to assemble whatever support is required to overcome any barriers to mathematical growth. It is possible to overcome learned helplessness and mathematical anxiety. In the recent case study of [12], the results reveal that mathematics resilience help learners to develop concentration, awareness of emotions and physiological needs (Self-Determination Theory). Building learning environment based on mathematics resilience develop learners' skills, competence and diminished mathematics anxiety over time.

Furthermore, achievement goals were conceptualized as the competence-relevant purposes or aims that individual strive for in achievement settings. These different purposes or aims are posited to lead to differential performance outcomes [13]. Achievement goals refer to the purposes for which a person engages in achievement behavior [14]. Achievement goals provide a framework to conceptualize motivation. Individuals were hypothesized to have different purposes or reasons for engaging in activity which probably influences their performance attainment.

The educational system faced unprecedented health crisis that completely transforms its initial landscape, while the challenge of improving mathematics performance still exists. This paper primarily aims to determine the relationship of mathematics resilience and achievement goals to mathematics performance of university students. It strives to gain better insight into the level of mathematics resilience and dominant achievement goals in this critical time of COVID-19 pandemic and implementation of alternative learning modalities.

\section{Methodology}

The descriptive-correlational research design was used in exploring nature of association of the variables of the study. The correlational research design is intended to find relationships between variables and predict future events based on current understanding. It also provides for the testing of planned relationships between and among factors and the making of forecasts [15].

The respondents were determined using total population sampling. It is a type of purposive sampling technique that gather the data of entire population that hold a set of characteristics, it was used the study since the population were relatively small and to produce valid conclusions. Overall, 69 second-year education students major in mathematics from Nueva Ecija University of Science and Technology (NEUST) take part in the study. The participants were enrolled in Calculus with Analytic Geometry course.

This study adapted the Mathematics Resilience Scale (SRS) [16], the instrument measures the students' attitudes toward studying mathematics, using three correlated factors such as Value, Struggle, and Growth. Furthermore, Achieve- 
ment Goal Questionnaire-Revised (AGQ-R) [17] was also used. It is composed four dimensions with three items each: mastery-approach goals, mastery-avoidance, performance-approach goals, and performance-avoidance goals. The instrument obtaining an optimal set of $2 \times 2$ achievement goal items. They were used as primary instrument of data gathering.

Moreover, the researcher used frequency count, percentage, mean, standard deviation, and Pearson's $r$ to statistically analyze the data.

\section{Results and Discussions}

\subsection{Mathematics Performance, Mathematics Resilience, and Achievement Goals}

\section{1) Mathematics Performance}

Table 1 shows the distribution of the students based on their mathematics performance. The data indicate that $22 \%$ or $31.88 \%$ of the respondents had a grade between 86 to 90 with a good verbal interpretation. Moreover, $21 \%$ or $30.43 \%$ of the students fall in the grade range of 91 to 95 , which can be considered very good. This means that a large proportion of the students performed good at and very good level in mathematics. On the other hand, $5 \%$ or $7.25 \%$ of the students performed poor $(76-80)$ in mathematics, while $4.35 \%$ performed very poorly (75 Below) in mathematics. It can be noted that only $5.80 \%$ performed excellently in mathematics.

This paper's results were consistent with the study [18], which found out that the majority of students performed very good academically, with an above-average level of study orientation. However, the results differed from the assessment conducted by Trends in International Mathematics and Science Study (TIMSS) in 2019, wherein the Philippines ranked very low in Mathematics and Science. The results were reasonable since the respondents of the study were teacher education students major in mathematics. Thus, it was expected that respondents have higher Mathematics performance as compared to general.

\section{2) Mathematics Resilience}

Table 2 shows that the students' level of mathematics resilience had a general weighted mean of 3.38; it was interpreted as a high level of mathematics resilience. Students with a high level of mathematics resilience have more remarkable persistence in learning mathematics in the face of adversity. In contrast, students' low-level resilience would reduce persistence despite adversity [19]. Mathematics resilience had three components; value, struggle, and growth.

The weighted mean of value was 3.64, with a standard deviation of 0.35 . This mathematics resilience component has the highest weighted mean compared to other components with the most negligible dispersion. It only means that students have a very high level of value to mathematics. Student with high-value levels perceive mathematics as an essential tool in achieving their current and future goals [16]. Thus, the majority of the students believe that mathematics valuable subject and is worth studying. 
Table 1. Mathematics performance.

\begin{tabular}{cccc}
\hline Grades & f & Percentage & Verbal Description \\
\hline $96-100$ & 4 & $5.80 \%$ & Excellent \\
$91-95$ & 21 & $30.43 \%$ & Very Good \\
$86-90$ & 22 & $31.88 \%$ & Good \\
$81-85$ & 14 & $20.29 \%$ & Fair \\
$76-80$ & 5 & $7.25 \%$ & Poor \\
75 Below & 3 & $4.35 \%$ & Very Poor \\
Total & 69 & $100.00 \%$ & \\
\hline
\end{tabular}

Table 2. Level of mathematics resilience.

\begin{tabular}{cccc}
\hline Mathematics Resilience & Weighted Mean & SD & General Weighted Mean \\
\hline Value & 3.6377 & 0.3464 & \\
Struggle & 3.4058 & 0.4217 & 3.3789 \\
Growth & 3.0932 & 0.4256 & \\
\hline
\end{tabular}

Moreover, the struggle has a weighted mean of 3.41 with a standard deviation of 0.42 . The data shows that students have a high-level persistence in learning mathematics. It only means that most of the student-respondents understand that learning Mathematics was not an easy path and it requires perseverance and dedication. Resilient learners recognize that struggle was part of developing mathematics proficiency; they acknowledge the need for experts' support and help.

Lastly, growth has a weighted mean of 3.09 with a standard deviation of 0.43 . It can be observed that growth has the lowest weighted mean and highest dispersion as compared to other scales of mathematics resilience, but it was still considered as a high level of growth. The data indicates that most of the students believe that their intelligence and ability to learn the subject matter can be further improved and developed through hard work and dedication. However, at a certain point, they still have some doubt with regards to their capabilities. Individuals with a growth mindset do not think they are special people born with the right to win. They are people who work hard, who learn how to keep their focus under pressure. People in a growth mindset do not just seek challenge, and they thrive on it [20].

\section{3) Achievement Goals}

Table 3 shows the general weighted mean and standard deviation of students' goal orientation used in learning mathematics. The data revealed that students' mastery-approach goals had an overall weighted average of 3.80 with a standard deviation of 0.27 , and mastery-avoidance had a mean of 2.99 with a standard deviation of 0.60 . On the other hand, performance-approach goals with an overall weighted mean of 3.13 and a standard deviation of 0.50 ; and performanceavoidance goals with an overall weighted mean of 3.15 and a standard deviation of 0.54 . 
Table 3. Weighted mean of student achievement goals.

\begin{tabular}{ccc}
\hline Achievement Goals & Weighted Mean & SD \\
\hline Mastery-Approach Goal & 3.8019 & 0.2701 \\
Mastery-Avoidance Goal & 2.9903 & 0.6022 \\
Performance-Approach Goal & 3.1256 & 0.4954 \\
Performance-Avoidance Goal & 3.1594 & 0.5381
\end{tabular}

It is apparent in the table above that mastery-approach goals had the highest general weighted mean and also with the lowest dispersion. Thus, the data only point out that most students practice mastery goals. It only signifies that most of the students strive to develop their skills to become competent in Mathematics. They usually engage in learning because they want to acquire new knowledge and learn as much as possible. In different circumstances, it must also note that some of the students also adapt mastery-avoidance goal. Students with mastery avoidance goals were expected to stay out of situations where they cannot understand. If students have mastery-avoidance goal, they were worried about not being able to complete the task.

The data also revealed that most student-respondents were adaptive to the performance-approach goals since their general weighted mean was also high. Taken together, these results suggest that several students strive to demonstrate that they have superior competence in statistics as compared to their classmates. Hence, some of the students were very competitive to gain public recognition. [21] stressed that in multiple goals perspective, individuals could adapt both mastery and performance-approach goals simultaneously that lead to positive learning outcomes. Performance-avoidance had the lowest weighted mean, indicating that only a few students adapt to this orientation. It can be concluded that only a tiny portion of the students studied their lessons in statistics since they do not want to create an impression of incompetence for themselves.

\subsection{Relationship of Mathematics Performance and Mathematics Resilience}

A correlational analysis was used to determine the existing relationship between mathematics resilience and mathematics performance. To test the study's hypothesis, Pearson $r$ moment product correlation was used, with a $5 \%$ level of significance (Table 4).

The statistical analysis indicates that value had a significant relationship to mathematics performance since the $\mathrm{p}$-values was less than 0.05 or $\mathrm{p}$-value $=$ 0.043. Thus, students with high level of value or appreciation to mathematics had better performance. Students with superior mathematics qualification tend to have high level of mathematics resilience scores [22].

Meanwhile, it was also found that struggle and growth had no direct correlation to mathematics performance ( $\mathrm{p}$-values $=0.540,0.817,0.598$ ). The results were similar to the study of [23], wherein the research study reveals no significant correlation between mathematics resilience and students' mathematics 
Table 4. Correlation of mathematics performance and mathematics.

\begin{tabular}{cccc}
\hline Mathematics Resilience & Performance & p-value & Verbal Interpretation \\
\hline Value & 0.225 & 0.043 & Significant \\
Struggle & -0.113 & 0.357 & Not Significant \\
Growth & 0.172 & 0.158 & Not Significant \\
\hline
\end{tabular}

Table 5. Correlation of mathematics performance and achievement goals.

\begin{tabular}{cccc}
\hline Achievement Goal & Performance & p-value & Verbal Interpretation \\
\hline Mastery-Approach & 0.304 & 0.011 & Significant \\
Mastery-Avoidance & 0.019 & 0.880 & Not Significant \\
Performance-Approach & 0.077 & 0.531 & Not Significant \\
Performance-Avoidance & 0.181 & 0.137 & Not Significant \\
\hline
\end{tabular}

achievement. It was a contradiction to assumptions that mathematics resilience influences the academic achievement of the students. Hence, further studies were needed to validate the construct and instrument used to measure mathematics resilience.

\subsection{Relationship of Mathematics Performance and Achievement Goals}

Pearson product-moment correlation coefficient was also utilized to test the relationship between mathematics performance and achievement goals. The analysis used a 5\% level of significance $95 \%$ confidence level. The results of the analysis indicate that only mastery-approach goal had a significant relationship to mathematics performance since its $\mathrm{p}$-value was less than 0.05 ( $\mathrm{p}$-value $=0.011$ ). Thus, students that strive to develop competence and gain mastery had better mathematic performance. Students with mastery goals seek to gain new knowledge and further develop their skills, leading to a lower test anxiety level. In addition, mastery goal-oriented exhibit an adaptive behavior pattern in which they strive to complete a task despite setbacks and treat failure as learning opportunities [24] (Table 5).

Furthermore, the statistical analysis also shows that mastery-avoidance, performance approach goal and performance-avoidance goal had no significant correlation to mathematics performance ( $\mathrm{p}$-value $=0.880,0.531,0.137$ ). It contradicts the findings of [25] that performance-based goals may provide beneficial indirect effects on achievement via academic self-concept. Thus, it implies that performance-approach goals are not a factor that contributes to higher mathematics performance. Likewise, the results were inconsistent with [26] findings, which revealed that students with a lower level of performance-avoidance goals tend to accomplish better academic achievement. The results suggest that Filipino students aim to excel relative to their peers and avoid the work to attain normative excellence. Thus, contrasting results need further studies to determine 
the role and functions of achievement goals to mathematics performance.

\section{Conclusions}

To conclude, student teachers performed good in mathematics. Therefore, student teachers were considered proficient in mathematics. It only means that teacher education students have developed fundamental knowledge, skills, and a core understanding of mathematics at this level. Likewise, most mathematics students have a high level of mathematics resilience. Thus, most of the mathematics student teachers had a positive attitude towards learning mathematics and high persistence despite challenges encountered. The majority of the students practice mastery goals in learning mathematics. It indicates that generally, students strive to develop their skills to become competent in statistics.

Mathematics resilience-value was statistically associated with the mathematics performance. Hence, student teachers who performed well in mathematics had higher appreciation and importance to mathematics. Meanwhile, struggle and growth had no enough evidences for its statistical significance.

Mastery-approach goal had significant positive association to mathematics performance. Therefore, student teachers who pursue frequently the mastery-approach goals were more likely to success in learning mathematics. On the other hand, mastery-avoidance goal, performance-approach goal and performanceavoidance goal had no direct significant relationship to mathematics performance.

\section{Conflicts of Interest}

The author declares no conflicts of interest.

\section{References}

[1] Baltà-Salvador, R., Olmedo-Torre, N. and Peña, M., et al. (2021) Academic and Emotional Effects of Online Learning during the COVID-19 Pandemic on Engineering Students. Education and Information Technologies, 26, 7407-7434. https://doi.org/10.1007/s10639-021-10593-1

[2] SEI-DOST and MATHTED (2011) Mathematics Framework for Philippine Basic Education. SEI-DOST \& MATHTED, Manila.

[3] Mullis, I.V.S., Martin, M.O., Foy, P., Kelly, D.L. and Fishbein, B. (2020) TIMSS 2019 International Results in Mathematics and Science. Boston College, TIMSS \& PIRLS International Study Center. https://timssandpirls.bc.edu/timss2019/international-results/

[4] Zhang, J., Zhao, N. and Kong, Q.P. (2019) The Relationship between Math Anxiety and Math Performance: A Meta-Analytic Investigation. Frontiers in Psychology, 10, Article No. 1613. https://doi.org/10.3389/fpsyg.2019.01613

[5] Namkung, J.M., Peng, P. and Lin, X. (2019) The Relation between Mathematics Anxiety and Mathematics Performance among School-Aged Students: A Meta-Analysis. Review of Educational Research, 89, 459-496. https://doi.org/10.3102/0034654319843494

[6] Ariyanto, L., Herman, T., Sumarmo, U. and Suryadi, D. (2017) Developing Mathe- 
matical Resilience of Prospective Math Teachers. Journal of Physics. Conference Series, 895, Article ID: 012062. https://doi.org/10.1088/1742-6596/895/1/012062

[7] Khine, M.S. and Areepattamannil, S. (2016) Non-Cognitive Skills and Factors in Educational Attainment. Sense Publishers, Dordrecht.

https://doi.org/10.1007/978-94-6300-591-3

[8] Adebayo, B. (2008) Cognitive and Non-Cognitive Factors: Affecting the Academic Performance and Retention of Conditionally Admitted Freshmen. Journal of College Admission, 200, 15-21.

[9] Tovar-García, E.D. (2017) The Impact of Perseverance and Passion for Long Term Goals (GRIT) on Educational Achievements of Migrant Children: Evidence from Tatarstan, Russia. Psicología Educativa, 23, 19-27. https://doi.org/10.1016/j.pse.2017.02.003

[10] Hutauruk, A. and Priatna, N. (2017) Mathematical Resilience of Mathematics Education Students. Journal of Physics: Conference Series, 895, Article ID: 012067. https://doi.org/10.1088/1742-6596/895/1/012067

[11] Lee, C. and Johnston-Wilder, S. (2017) The Construct of Mathematical Resilience. In: Xolocotzin, U., Ed., Understanding Emotions in Mathematical Thinking and Learning, Academic Press, Cambridge, 269-291. https://doi.org/10.1016/B978-0-12-802218-4.00010-8

[12] Johnston-Wilder, S., Lee, C. and Mackrell, K. (2021) Addressing Mathematics Anxiety through Developing Resilience: Building on Self-Determination Theory. Creative Education, 12, 2098-2115. https://doi.org/10.4236/ce.2021.129161

[13] Elliot, A.J., Shell, M.M., Henry, K.B. and Maeier, M. (2005) Achievement Goals, Performance Contingencies, and Performance Attainment: An Experimental Test. Journal of Educational Psychology, 97, 630-640. https://doi.org/10.1037/0022-0663.97.4.630

[14] Pahljina-Reinić, R. and Kolić-Vehovec, S. (2017) Average Personal Goal Pursuit Profile and Contextual Achievement Goals: Effects on Students' Motivation, Achievement Emotions, and Achievement. Learning and Individual Differences, 56, 167174. https://doi.org/10.1016/j.lindif.2017.01.020

[15] Stangor, C. (2011) Research Methods for the Behavioral Sciences. 4th Edition, Cengage, Mountain View, CA.

[16] Kooken, J., Welsh, M., McCoach, D., Johnston-Wilder, S. and Lee, C. (2015) Development and Validation of the Mathematical Resilience Scale. Measurement and Evaluation in Counseling and Development, 49, 217-242.

https://doi.org/10.1177/0748175615596782

[17] Elliot, A.J. and Murayama, K. (2008) On the Measurement of Achievement Goals: Critique, Illustration, and Application. Journal of Educational Psychology, 100, 613 628. https://doi.org/10.1037/0022-0663.100.3.613

[18] Guinocor, M., Almerino, P., Mamites, I., Lumayag, C., Villaganas, M.A. and Capuyan, M. (2020) Mathematics Performance of Students in a Philippine State University. International Electronic Journal of Mathematics Education, 15, em0586.

[19] Kooken, J., Welsh, M., Mccoach, B. Johnson-Wilder, S. and Lee, C. (2013) Measuring Mathematical Resilience: An Application of the Construct of Resilience to the Study of Mathematics. American Educational Research Association (AERA) 2013 Annual Meeting. Education and Poverty: Theory, Research, Policy and Praxis, 27 April-1 May 2013, San Francisco.

[20] Dweck, C.S. (2006) Mindset: The New Psychology of Success. Random House, Manhattan. 
[21] Elmer, R. and Allan, B. (2013) Are Two Achievement Goals Better than One? Filipino Students' Achievement Goals, Deep Learning Strategies and Affect. Learning and Individual Differences, 27, 97-101.

[22] Duah, F. (2017) Mathematics Resilience: What Is Known in the Pre-Tertiary Mathematics Education Research and What We Have Found Researching Non-Mathematics-Specialists. Proceedings of the British Society for Research into Learning Mathematics, 37, $6 \mathrm{p}$.

[23] Rokhmah, K., Retnawati, H. and Solekhah, P. (2019) Mathematical Resilience: Is that Affecting the Students' Mathematics Achievement? Journal of Physics. Conference Series, 1320, Article ID: 012036.

https://doi.org/10.1088/1742-6596/1320/1/012036

[24] Andreea, S. and Crenguța, O. (2015) Test Anxiety and Achievement Goal Orientations of Students at a Romanian University. Procedia-Social and Behavioral Sciences, $180,1673-1679$

[25] Niepel, C., Brunner, M. and Preckel, F. (2014) Achievement Goals, Academic SelfConcept, and School Grades in Mathematics: Longitudinal Reciprocal Relations in above Average Ability Secondary School Students. Contemporary Educational Psychology, 39, 301-313.

[26] Sorić, I., Penezic, Z. and Burić, I. (2017) The Big Five Personality Traits, Goal Orientations, and Academic Achievement. Learning and Individual Differences, 54, 126 134. 